\title{
Descriptive and evaluative judgment processes: Behavioral and electrophysiological indices of processing symmetry and aesthetics
}

\author{
THOMAS JACOBSEN and LEA HÖFEL \\ Universität Leipzig, Leipzig, Germany
}

\begin{abstract}
Descriptive symmetry and evaluative aesthetic judgment processes were compared using identical stimuli in both judgment tasks. Electrophysiological activity was recorded while participants judged novel formal graphic patterns in a trial-by-trial cuing setting using binary responses (symmetric, not symmetric; beautiful, not beautiful). Judgment analyses of a Phase 1 test and main experiment performance resulted in individual models, as well as group models, of the participants' judgment systems. Symmetry showed a strong positive correlation with beautiful judgments and was the most important cue. Descriptive judgments were performed faster than evaluative judgments. The ERPs revealed a phasic, early frontal negativity for the not-beautiful judgments. A sustained posterior negativity was observed in the symmetric condition. All conditions showed late positive potentials (LPPs). Evaluative judgment LPPs revealed a more pronounced right lateralization. It is argued that the present aesthetic judgments engage a two-stage process consisting of early, anterior frontomedian impression formation after $300 \mathrm{msec}$ and right-hemisphere evaluative categorization around $600 \mathrm{msec}$ after onset of the graphic patterns.
\end{abstract}

A considerable portion, if not the majority, of everyday judgment processes can be considered evaluative, rather than descriptive, in character. In the present study, we combined behavioral and event-related brain potential (ERP) data in order to compare these descriptive and evaluative judgment processes. Our goal was to investigate the processing characteristics and temporal courses of both types of judgments while isolating judgmental processes from perceptual ones. To this end, we used the same set of novel formal graphic stimuli in both judgment tasks, counterbalanced across participants. Participants made symmetry judgments in the descriptive task and aesthetic judgments of beauty in the evaluative judgment task.

\section{Descriptive and Evaluative Cognition}

The distinction between descriptive and evaluative cognition that has evolved in the wake of the cognitive revolution is prevalent in contemporary cognitive theories (e.g., Gardner, 1985). Evaluative cognition processes the individual, subjective value of an entity; descriptive cognition is nonevaluative. Descriptive judgments may use external references that can be objectified.

The authors are very grateful to Erich Schröger for his continued advice and support of this project, to Ricarda Schubotz, and to two anonymous reviewers for helpful comments on an earlier version of the manuscript. Aspects of this work were reported at the XVI Congress of the International Association of Empirical Aesthetics and appeared in the conference special issue of Empirical Studies of the Arts, 19(2), 2001. This work was partly supported by DFG Grant JA1009/2-1. Address correspondence to T. Jacobsen, BioCog-Kognitive \& Biologische Psychologie, Institut für Allgemeine Psychologie, Universität Leipzig, Seeburgstraße 14-20, 04103 Leipzig, Germany (e-mail: jacobsen@uni-leipzig.de).
Mandler and Shebo (1983) investigated the relative speed of evaluative and descriptive judgments in two experiments. In Experiment 1, lexical decision judgments were compared with liking judgments, and in Experiment 2, paintings were judged for prior encounters and for liking. In both experiments, descriptive judgments were faster than evaluative judgments. The authors concluded that knowing (descriptive processing) and liking (evaluative processing) are based on different aspects of the same underlying representation. They argued against the view that conceptualizes knowledge and affect as two distinct, qualitatively different systems in which preference judgments should be immediately accessible without any mediating cognitive processes (e.g., Zajonc, 1980; see also Mandler, 1982).

Memory representations of descriptive and evaluative aspects of entities have been studied extensively in the tradition of attitude research. Knowledge systems have been postulated that consist of descriptive cognitive components and valence components to form the attitude toward an entity (see, e.g., Petty, Wegener, \& Fabrigar, 1997, for a review). Because the present study concerns judgment processes, we used novel stimuli in both judgment conditions in order to preclude mere memory retrieval. Participants were required to process the symmetry of the patterns on line and to evaluate the beauty of the material.

Symmetry judgments. Symmetry judgments require participants to determine whether a stimulus is symmetric or not symmetric. In a number of studies, symmetry judgments have been used successfully as descriptive cognitive tasks. Using repetition priming, Kersteen-Tucker (1991) 
investigated symmetric (vs. not-symmetric) polygons. Symmetric stimuli revealed more persistent priming than did not-symmetric ones. Pashler (1990) investigated the coordinate frame for symmetry detection and object recognition, in a series of experiments. Among other effects, he found an overall advantage of vertical symmetry and substantial facilitative effects of precuing. Wenderoth (1994) also reported enhanced salience of vertical symmetry. In the present study, symmetry was varied so that stimuli that appeared to be regular and orderly were also symmetric and irregular ones were not; that is, the descriptive symmetry judgment task was designed to be relatively easy (cf. Mandler \& Shebo, 1983).

Aesthetic judgments. Human aesthetic processing consists of a complex set of mechanisms. Since Fechner's seminal writings (1876), a host of factors have been reported as influencing aesthetic judgment (e.g., Berlyne, 1971, 1974), including stimulus symmetry (e.g., Eisenman, 1967; Eisenman \& Gellens, 1968), complexity (e.g., Berlyne, 1963, 1970, 1974; Eisenman, 1967; Eisenman \& Gellens, 1968; Eysenck \& Hawker, 1994), novelty (e.g., Berlyne, 1970, 1974; Cupchik, 1992), and semantic content as opposed to formal qualities of design (e.g., Cupchik, 1992; Martindale, 1988). In addition, emotional factors (e.g., Konecni, 1979; Schwarz, 1988), interestingness (e.g., Berlyne, 1974), appeal to social status (e.g., Konecni, 1979; Ritterfeld, 2002), and cultural or economic background in general (e.g., Konecni, 1979) are known to influence aesthetic judgments. Here, novel formal graphic material from Jacobsen and Höfel (2002) was selected, in which stimulus symmetry and complexity are varied in order to establish good experimental control.

\section{Aesthetic Judgment Analysis}

In the present study, we focus on descriptive symmetry and evaluative aesthetic judgment processes by using a group-level approach. Previous research, however, though rooted mainly in the nomothetic approach, the finding and postulation of general rules, has also revealed individual differences in aesthetic judgments (e.g., Fechner, 1876; Jacobsen, 2002; Whitfield, 1984). In order to analyze individual differences, we used the approach of Jacobsen (in press). For capturing judgment strategies, we adopted the framework of social judgment theory, which defines judgment as a process that involves the integration of information from a set of cues into a judgment about some distal state of affairs (Hammond, Stewart, Brehmer, \& Steinmann, 1975). The theory provides a foundation for judgment analysis, and it allows one to derive individual as well as group models. In accordance with Stewart (1988, p. 41), judgment analysis is defined as "using statistical methods to derive algebraic models of the judgment process." This is a paramorphic way to model judgment, which is an input-output mapping of the judgment process under the premise that the material to be evaluated is perceptually salient. From this perspective, the perceptual process itself does not need to be modeled and only input to and output from the judgment process must be considered. See Cooksey (1996) for a comprehensive introduction to judgment analysis.

Here, we used judgment analysis to assess the participants' judgmental systems; we were particularly interested in learning how the participants would make aesthetic judgments during the Phase 1 test and the main experiment. This allowed us to determine the degree of correlation between stimulus features and behavioral performance, which is important for comparing both judgmental tasks. Later, ERP averages were based on individual preferences. Thus, we controlled for individual differences at the group level.

\section{Electrophysiology of Evaluative Cognition}

An electrophysiology of evaluative processing has been evolving in recent years. In a number of studies, Cacioppo and coworkers (Cacioppo, Crites, Berntson, \& Coles, 1993; Crites \& Cacioppo, 1996; Crites, Cacioppo, Gardner, \& Berntson, 1995; Ito \& Cacioppo, 2000) have reported a centroparietally preponderant late positive potential(LPP) reflecting operations of evaluative categorizations. In an oddball paradigm (Cacioppo, Crites, Gardner, \& Berntson, 1994), participants were presented with six traits and had to perform two-alternative evaluative judgments. Evaluative inconsistent traits evoked larger amplitude LPPs than did consistent ones. Further research has revealed comparable effects for various attitude objects (e.g., Schupp et al., 2000). There is a manifest negativity bias reflected by higher amplitude LPPs for negative evaluations. The LPP shows a hemispheric asymmetry with larger amplitudes over the right hemisphere of the scalp for evaluative judgments as opposed to descriptive tasks. Cacioppo and colleagues have concluded that neural sources subserving evaluative categorizations are at least partially independent of those enabling descriptive processes. Their research has largely focused on the processing of attitudes (see Ito \& Cacioppo, 1999, for a review of research on the psychophysiology of evaluative processing). ${ }^{1}$

\section{The Present Study}

The temporal course and the processing characteristics of descriptive symmetry judgments and evaluative aesthetic judgments of novel graphic patterns were investigated using combined behavioral, electrophysiological, and judgment analysis measures. Participants judged the patterns in a mixed design with trial-by-trial cuing of the binary judgment tasks while the EEG was continuously recorded. The material, perceptually salient, consisted of a well-defined range of perceptual cues, in order to keep the task purely judgmental in nature (cf. Hammond et al., 1975). Stimuli were counterbalanced across participants and thus served as their own controls. Symmetry and complexity were varied in a large stimulus set, and the procedure included a Phase 1 test. Here, the participants were preexposed to the novel stimuli so that they could form judgments in relation to the entire item set rather than basing them on single sequential presentations of stimuli. Judgment analysis was employed to 
derive individual case models of the judges' cognitive systems as well as group models at Phase 1 test and in the main experiment.

ERP deflections elicited by evaluative processing that is qualitatively different from descriptive processing should show an involvement of distinct neural generators. Consequently, morphological and topographical differences in the ERP waveforms between both tasks were predicted. On the basis of the work of Cacioppo and colleagues (see above), it was predicted that evaluative judgment processes should reveal a stronger right-hemisphere pronunciation of the late positive potential (LPP), if the latter reflected processes that would generalize to the present experimental setting. In addition, the descriptive symmetry judgment task was predicted to show stronger occipital involvement reflecting processes of more detailed visual analysis. Also, it was predicted that group models and individual case models replicate previous reports of symmetry and complexity as determinants of aesthetic judgments. In addition, on the basis of reports of individual differences in aesthetic judgment (e.g., Fechner, 1876; Jacobsen, 2002, 2004; Whitfield, 1984) individual judgmental variation was predicted.

\section{METHOD}

\section{Participants}

Nine young adults ( 6 men) participated in the experiment for partial fulfillment of course requirements. All were 2nd-year psychology students at the University of Leipzig. Eight of them were righthanded, 1 left-handed (Oldfield, 1971). Their mean age was 22.4 years, ranging from 20 to 26 . None had received professional training in the fine arts or participated in a similar experiment before. The participants reported normal or corrected-to-norm al visual acuity and no known neurological condition. Three additional participants had to be excluded from the analysis of the main experiment because of technical errors leading to a high rate of EEG artifacts (1), poor performance (30\% errors) in the symmetry judgment task (1), or both (1).

\section{Material}

The 252 black and white stimuli from Jacobsen and Höfel (2002) were used. Each consisted of a solid black circle ( $8.8 \mathrm{~cm}$ in diameter) featuring a centered quadratic rhombic cutout and 86-88 basic graphic elements (small black triangles) arranged within the rhomb according to a grid and resulting in a graphic pattern. The basic elements were arranged so that geometric figures such as triangles, squares, rhombuses, and horizontal, vertical, or oblique bars were created. The overall luminance was identical for all stimuli. Half (130) were symmetric; that is, a maximum of two mirroring operations, given four possible symmetry axes, was permitted. The other half of the stimuli were clearly not symmetric. Figure 1 shows 12 examples of the material.

The following features of the patterns were extracted for use in the judgment analysis: mirrored at one axis (one operation sufficient), mirrored at two axes (each one of two possible operations sufficient), mirrored over two axes (two operations required), regular composition, number of elements, horizontal or vertical bars, large horizontal or vertical bars, small horizontal or vertical bars, oblique bars, large oblique bars, small oblique bars, squares, large squares, small squares, rhombuses, large rhombuses, small rhombuses, triangles, large triangles, and small triangles. These were considered to be perceptual cues that could be used by the participants in deriving their judgments. Accordingly the features were employed in

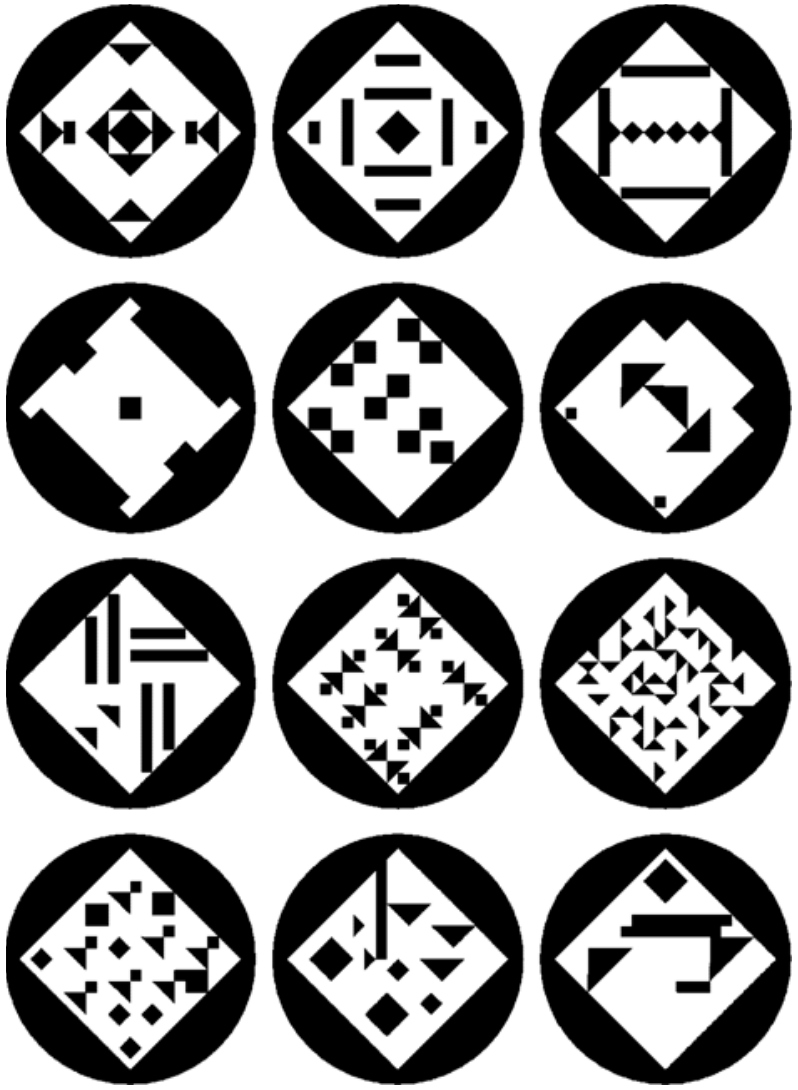

Figure 1. Stimulus examples. The graphic patterns in rows 1 and 2 are symmetric, ranging from most beautiful to least beautiful (line by line). Patterns in rows 3 and 4 are not symmetric, also ranging from most beautiful to least beautiful.

the judgment analysis (i.e., they were introduced as predictors in the multiple regression analysis; Jacobsen, 2004). See the Appendix for the intercorrelation matrix of all 20 features.

\section{Apparatus}

The experiment was run on an IBM-compatible computer with DOS, using the ERTS experiment programming shell. The stimuli were presented on a Sony Multiscan 200PS SVGA monitor. Judgment responses were made and latencies captured using the right and left buttons of a four-button response keyboard triggering the ERTS reaction time clock via the ERTS ExKey-Logic. An electrically shielded and sound-attenuated experimental chamber (International Acoustic Company) was used. EEG was recorded via capmounted Ag/AgCl electrodes (Falk Minow Services). A 32-channel NeuroScan SynAmps EEG amplifier was used for EEG signal amplification and digitizing. The NeuroScan Acquire software was used for recording and was also run on a PC-type computer. Offline signal processing was carried out on computer work stations running EEP 3.0 (MPI-CNS; ANT-Software) under Linux.

\section{Procedure}

This study was conducted in two parts. The first part, the Phase 1 test, served to familiarize the participants with the stimulus set.

Phase 1 test. The participants were presented with the complete set of 252 graphic patterns printed on cards in randomized order. They were instructed to judge them according to the picture's aesthetic value. Here, the word beautiful was explicitly mentioned (Ja- 
cobsen, in press). The participants were advised to take their time and to spread the patterns out in front of them so that they could get a good overall impression. They were instructed to create three bins: one of at least 75 beautiful patterns, one of at least 75 not beautiful patterns, and a remaining category of indifferent pictures. This last bin could contain zero elements, if that was preferred. There was an interval of a maximum of 3 days between the Phase 1 test and the main experiment. The participants reported no difficulties in dissociating aesthetic and nonaesthetic patterns.

Main experiment. The experimental design was as follows. The type of judgment and symmetry status of the stimuli were fully crossed. Stimuli were pseudo-randomly assigned to an experimental condition. Assignments were counterbalanced across participants. The item sequence was pseudo-randomized according to the following constraints: a maximum of 3 trials of a task (symmetry, aesthetics) or answer category (yes, no) in sequence. A block consisted of 63 trials. Participants were randomly assigned to two possible response key assignments (no/yes, yes/no).

The main experiment was structured as follows. All stimuli were presented to the participants in randomized order on the computer monitor during electrode application for a second time. The participants were told that they would be asked to judge the patterns with regard to symmetry and aesthetic value contingent on a precue during the recording session. Instructions concerning the symmetry axes were given. The participants were comfortably seated in the dimly lit chamber. A block of 20 practice trials was administered using patterns (10 symmetric and 10 not symmetric) and trial structure equivalent to those for the main experiment. After a short break for questions, the main experiment was carried out in four blocks. An experimental session lasted approximately $1 \mathrm{~h}$ (plus additional time for electrode application and removal).

Each trial began with a screen-centered fixation cross presented in light gray against a black background for $800 \mathrm{msec}$. A $1000-\mathrm{Hz}$ 200-msec warning tone simultaneously accompanied the fixation mark. A cue $(\ddot{\mathrm{A}}, \mathrm{S})$ indicating either the task aesthetic or the task symmetry judgment as applicable to the following target stimulus then appeared at the center of the screen for 1,200 msec inside a black frame. This frame covered the screen, except for a light gray (RGB 60, 60, 60) cutout $15.2 \times 11.3 \mathrm{~cm}$. It remained on the screen until the end of the trial. Following the cue, the frame remained empty for $800 \mathrm{msec}$, to be followed by the target presentation for $3,000 \mathrm{msec}$. The pattern was presented centered within the frame at a viewing distance of $120 \mathrm{~cm}$, resulting in visual angles of $4.3^{\circ}$. Judgment responses and latencies were recorded during target presentation. The intertrial interval was $800 \mathrm{msec}$ plus an additional variable exponentially distributed interval (mean length, $400 \mathrm{msec}$; maximum length, $800 \mathrm{msec}$ ).

\section{Electrophysiological Recordings}

The electroencephalogra $\mathrm{m}$ (EEG) was continuously recorded from 25 sites (FP1, FPz, FP2, F7, F3, Fz, F4, F8, FC5, FC6, T7, C3, Cz, C4, T8, CP5, CP6, P7, P3, Pz, P4, P8, O1, Oz, O2) according to the extended 10-20 system (American Electroencephalograph ic Society, 1991). In addition, electrical activity was recorded at both mastoids. The reference electrode was placed on the tip of the nose, the ground electrode at FC2. Electroocular activity was recorded from two bipolar channels. The vertical EOG was recorded from the right eye by supra- and infraorbital electrodes. The horizontal EOG was recorded from electrodes lateral to the outer canthi. Impedances were kept below $4 \mathrm{k} \Omega$. On-line filtering was carried out using a $0.05-\mathrm{Hz}$ highpass, a $40-\mathrm{Hz}$ low-pass, and a $50-\mathrm{Hz}$ notch filter. The signal was digitized with a 16-bit resolution at a sampling rate of $250 \mathrm{~Hz}$.

\section{Data Analysis}

In the Phase 1 test, participants sorted the stimuli into three bins according to the instructions. The bins were ordered from not beautiful to beautiful. The normalized median of the quantile of the pic- ture's bin was assigned to the stimulus as its judgment value (McCall, 1939). For the purposes of individual judgment analysis (see, e.g., Cooksey, 1996), these values were entered into a constrained stepwise multiple regression as the criterion along with the stimulus features (cues; see above and the Appendix) as predictors. The cue explaining most of the criterion variance was entered into the model first. Additional cues, providing incremental explanation of variance $(p<.001)$, were entered only if they did not show a substantial cue-cue correlation (>.28; see the Appendix) with already entered cues. The same method was used for computing the group model on the basis of the average judgment values.

During the main experiment, two bins were available for judgment responses (beautiful/not beautiful). An individual case model and a group model were derived using the same method as that for the Phase 1 test.

All continuous EEG records were filtered off line via a band-pass with a finite impulse response filter (FIR) with the following specifications: 8,001 points, critical high-pass frequency of $0.2 \mathrm{~Hz}$, critical low-pass frequency of $25 \mathrm{~Hz}$ (corner frequencies, 3db attenuation, of $0.2 \mathrm{~Hz}$ and $25 \mathrm{~Hz}$ ). Artifacts were rejected using a standard deviation criterion in a sliding window of $200 \mathrm{msec}$ (vertical EOG, 40; horizontal EOG, FPz, Cz, and both mastoids, 30). Contaminated epochs were excluded from further analysis.

Event-related potentials of 1,500-msec length and featuring a 200-msec prestimulus baseline were computed separately for all four conditions for each individual participant. Grand averages were subsequently computed from the individual-subject averages. The ERP quantification routine consisted of several steps. All analyses were based on individual mean amplitudes in the given time window at the respective electrode locations. First, substantial effects were revealed through visual inspection (see note 1). For each of these time windows, a repeated measures analysis of variance (ANOVA) was conducted with the factors task (aesthetic, symmetry), answer (yes, no), anterior/posterior scalp location (FP-line, F-line, C-line, P-line, O-line), and lateral scalp location (left [FP1, F3, C3, P3, O1], midline, right [FP2, F4, C4, P4, O2]). That is, 15 electrodes were used in a $3 \times 5$ grid. Subsequent ANOVAs were performed to localize the effects. If applicable, error percentages reflecting Greenhouse-Geisser $(\mathrm{G}-\mathrm{G})$ corrected degrees of freedom and $\mathrm{G}-\mathrm{G}$ epsilon $(\varepsilon)$ values are reported. Normalized data were derived, using vector length scaling according to McCarthy and Wood (1985).

\section{RESULTS}

\section{Judgment Analysis}

Table 1 gives the paramorphic individual case models for 9 participants in the Phase 1 test and the main experiment as well as the model for the group average data. Standardized regression coefficients and multiple regression coefficients $(R)$ are shown. The judgment stability (i.e., the pre-/posttest correlation) was $r=.76$.

The following predictors were included in at least one of the models at one of the two tests: mirrored at one axis, mirrored at two axes, mirrored over two axes, regular pattern, number of elements, horizontal or vertical bars, oblique bars, large oblique bars, small oblique bars, squares, large squares, triangles, large triangles. The following predictors were not included in a model at all: small triangles, large horizontal or vertical bars, small horizontal or vertical bars, small squares, rhombuses, large rhombuses and small rhombuses.

As predicted, symmetry was found to be the most important stimulus feature determining participants' aes- 


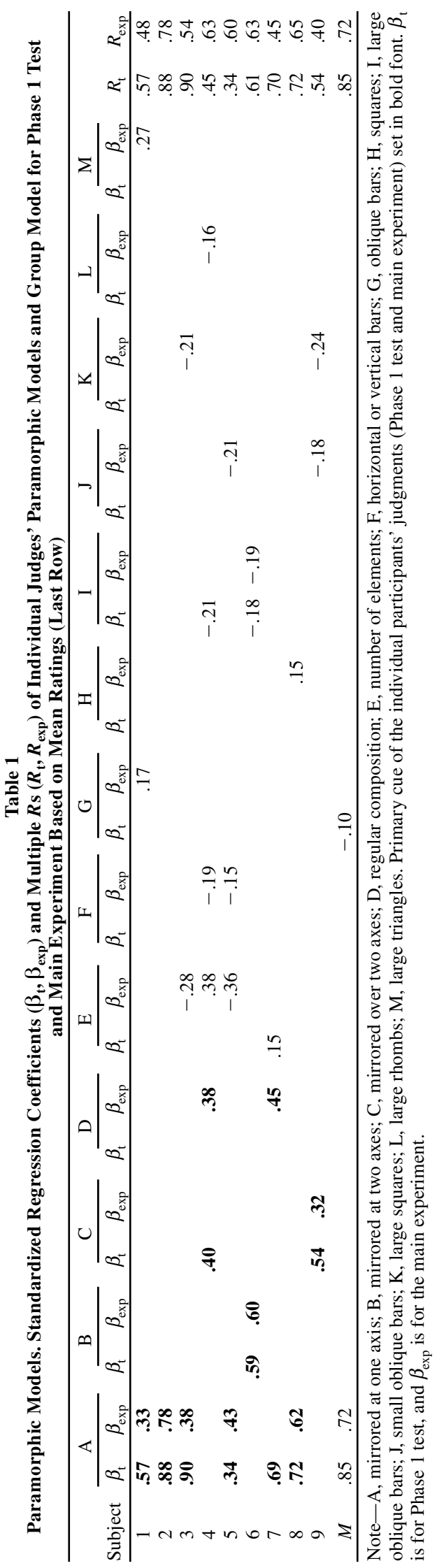

thetic judgments. In general, participants showed agreement that symmetric pictures were more beautiful than the others. The group model also reflected this fact. In addition, the individual case models revealed consistent and stable interindividual differences. All participants used symmetry cues as the most important stimulus feature determining beauty in a positive direction. Six of them relied on symmetry cues as the sole substantial factor influencing their judgments. For them, a symmetric pattern was more beautiful. Moreover, individual beta weights of symmetry cues ranged from .34 to .90 , revealing considerable variation of cue use; that is, the importance of symmetry cues for individual judges differed. These interindividual differences were leveled by the group model. Hence, detailed capturing of individual judgment policies provides a more thorough account of aesthetic judgment policies for these stimuli.

Furthermore, the number of elements in a pattern, a measure of complexity, was entered into four individual models. Two participants considered a larger number of elements in a pattern more beautiful, whereas 2 participants had the opposite strategy. The number of large oblique bars was entered into three models as a negative predictor.

A number of stimulus features (e.g., small triangles or small squares) were not used by the participants to derive their judgments. Participants revealed differences in linear predictability. Multiple $R$ s ranged from .34 to .90 , a range of explained judgmental variance from $12 \%$ to $81 \%$. The group model showed $72.3 \%$ of linearly explained variance, thus leveling the interindividual difference and hiding that fact. The averaging procedure treated individual differences in the aesthetic judgment as noise and thus canceled them out. Furthermore, differences in explained variance are typically interpreted as an index of strategy use (Stewart, 1988). Participants with a high linear predictability used systematic judgment strategies, whereas linearly unpredictable judges most likely employed highly configural cue combinations (Brehmer \& Joyce, 1988; Cooksey, 1996).

\section{Behavioral Performance}

In the main experiment, $89.3 \%$ of all symmetry judgment responses were correct. There were $10.1 \%$ erroneous responses ( $0.6 \%$ nonresponses). Aesthetic judgment responses showed $0.7 \%$ nonresponses. Mean response times (computed for correct trials only), standard deviations, and error percentages are given in Table 2.

The descriptive symmetry judgments were performed faster than the evaluative aesthetic judgments. A repeated measures analysis of variance (ANOVA) over the judgment latencies with the factors judgment task (symmetry, aesthetics) and answer (yes, no) revealed a significant effect of task $\left[F(1,8)=9.16, M S_{\mathrm{e}}=18,444.9, p=.016\right]$. No other effect was significant: answer, $F<1$; task $\times$ answer $\left[F(1,8)=3.4, M S_{\mathrm{e}}=13,158.8, p>.1\right]$. An ANOVA over the symmetry judgment errors revealed no significant effect $(F<1)$. Of the stimuli under the aesthetic judgment task, $42.8 \%$ were judged as beautiful, $56.5 \%$ as not beautiful; this difference was not statistically significant $(F<1)$. 
Table 2

Mean Judgment Latencies (RTs, in Milliseconds), Standard Deviations (SDs), and Percent Judgment Errors (\% E) for Correct Symmetry Responses and RTs and SDs for Aesthetic Judgment Responses

\begin{tabular}{|c|c|c|c|c|c|}
\hline \multirow[b]{3}{*}{ Answer } & \multicolumn{5}{|c|}{ Judgment } \\
\hline & \multicolumn{3}{|c|}{ Symmetry } & \multicolumn{2}{|c|}{ Aesthetic } \\
\hline & RT & $S D$ & $\% \mathrm{E}$ & RT & $S D$ \\
\hline Yes & 1,013 & 317 & 8.1 & 1,221 & 378 \\
\hline No & 1,044 & 248 & 6.6 & 1,111 & 298 \\
\hline
\end{tabular}

Note $-N=9$.

\section{Electrophysiological Data}

An average of $5.69 \%$ of the trials per participant was rejected prior to ERP computation (range, $1.66 \%-10.74 \%$ ). The ERPs in all four conditions (symmetric, not sym- metric, beautiful, not beautiful) showed identical, orderly P1 and N1 components (Figure 2). The waveforms started to differ at approximately $250 \mathrm{msec}$ after stimulus onset. At frontal sites, a more negative going phasic deflection was observed for the not-beautiful judgments from about 300 to $400 \mathrm{msec}$ after stimulus onset. At parietal and occipital sites, a sustained, more negative going waveform developed for the symmetric condition after $250 \mathrm{msec}$. A late positive potential (LPP) with righthemisphere pronunciation developed for all conditions peaking at around $600 \mathrm{msec}(\mathrm{Pz})$. The right lateralization was larger for the evaluative aesthetic condition.

Early frontal negativity. The frontal negativity for the not-beautiful judgments was analyzed in the time window between 300 and $400 \mathrm{msec}$. A potential map of the frontal negativity effect under the aesthetic judgment
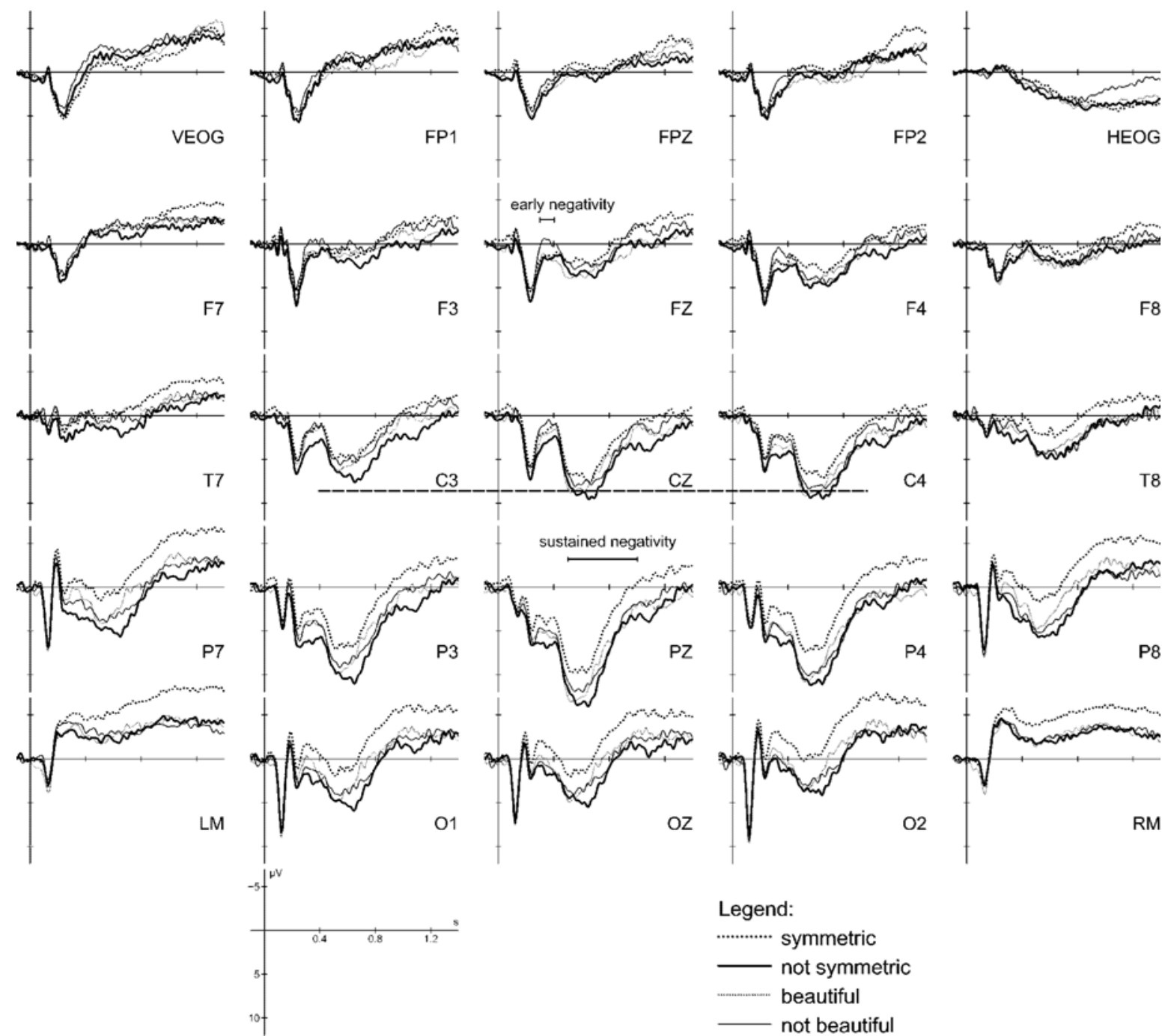

Legend:

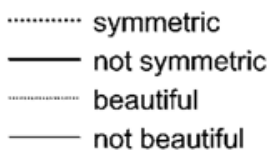

Figure 2. Grand average event-related brain potentials. Four conditions are shown: descriptive symmetry judgments (symmetric, not symmetric) and evaluative aesthetic judgments (beautiful, not beautiful). Stimuli were presented in a mixed design with task precuing (symmetry or aesthetic judgment). ERPs show the first $\mathbf{1 , 4 0 0} \mathrm{msec}$ of stimulus presentation and a 100 -msec prestimulus baseline. $(N=9$.) 


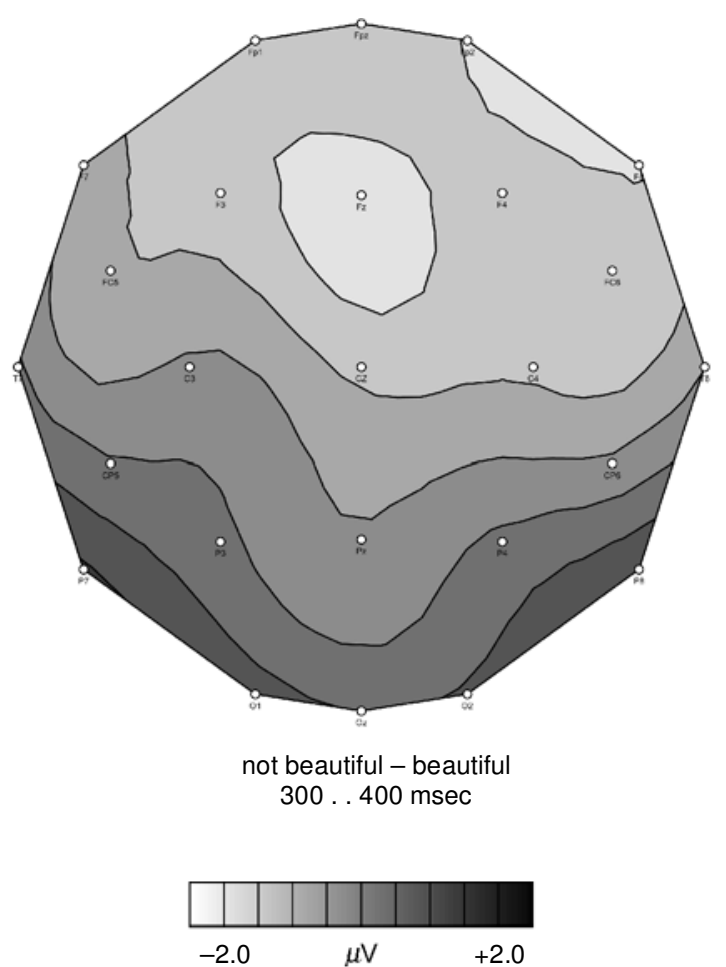

Figure 3. Isopotential contour plot, frontal negativity effect in the evaluative aesthetic judgment condition. Mean difference potentials were plotted, not-beautiful minus beautiful judgments in the time window from 300 to 400 msec after stimulus onset.

task is given in Figure 3 (not beautiful, beautiful). The overall analysis revealed interactions of task $\times$ answer $\left[F(1,8)=8.96, M S_{\mathrm{e}}=21.36, p=.018\right]$, task $\times$ position $\left[F(4,32)=3.38, M S_{\mathrm{e}}=3.16, \varepsilon=.5, p=.06\right]$, and for answer $\times$ position $\left[F(4,32)=9.82, M S_{\mathrm{e}}=3.62, \varepsilon=.4, p=\right.$ .0038]. It was further investigated using an ANOVA at $\mathrm{Fz}$ in the same time window with the factors task (symmetry, aesthetics) and answer (yes, no) which revealed a significant interaction $\left[F(1,8)=10.43, M S_{\mathrm{e}}=0.95, p=\right.$ .012]. No other effect was significant [task, $F(1,8)=$ $1.42, M S_{\mathrm{e}}=6.21, p=.26$; and answer, $F(1,8)=2.92$, $\left.M S_{\mathrm{e}}=1.65, p=.13\right]$. The interaction was further investigated for task, revealing a strong effect of answer under the aesthetics task $\left[F(1,8)=9.11, M S_{\mathrm{e}}=1.56, p=.016\right]$ and no effect $(F<1)$ under the symmetry task. Not-beautiful judgments were accompanied by an early phasic frontocentral negative deflection, relative to the other three conditions.

Posterior sustained negativity. There was a sustained posterior negative deflection elicited in the symmetrical condition under the symmetry judgment task from 600 to $1,100 \mathrm{msec}$ after stimulus onset. A potential map of the posterior sustained ERP effect under the symmetry judgment task is given in Figure 4. It was mapped out as a negativity effect (symmetric - not symmetric) on the basis of the subsequent analysis. The overall analysis revealed interactions for task $\times$ answer $[F(1,8)=$ $\left.12.88, M S_{\mathrm{e}}=18.21, p=.0071\right]$ and answer $\times$ position $\left[F(4,32)=5.83, M S_{\mathrm{e}}=5.86, \varepsilon=.53, p=.01\right]$. An ANOVA at Pz with the factors task (symmetry, aesthetics) and answer (yes, no) revealed a significant main effect of answer $\left[F(1,8)=8.97, M S_{\mathrm{e}}=3.92, p=.017\right]$ and a significant interaction $\left[F(1,8)=16.10, M S_{\mathrm{e}}=1.98, p=\right.$ $.0039]$. There was no main effect of task $[F(1,8)=1.04$, $\left.M S_{\mathrm{e}}=4.61, p=.34\right]$. The interaction was further investigated for task, revealing a strong effect of answer under the symmetry task $\left[F(1,8)=34.65, M S_{\mathrm{e}}=1.93, p=\right.$ $.0004]$ and no effect $(F<1)$ under the aesthetics task.

This ERP effect and the early frontal negative deflection constitute a double dissociation between descriptive symmetry and the evaluative aesthetic judgments.

Hemispheric asymmetry. A stronger ERP rightlateralization effect was observed in the evaluative aesthetic judgment condition from 440 to $880 \mathrm{msec}$ after stimulus onset. A potential map of the right-lateralization effect for the evaluative aesthetic judgment task is given in Figure 5 (aesthetic judgment - symmetry judgment). The overall analysis revealed interactions for task $\times$ answer $\left[F(1,8)=14.57, M S_{\mathrm{e}}=14.55, p=.0051\right]$ and task $\times$ lateral $\left[F(2,16)=7.32, M S_{\mathrm{e}}=0.63, \varepsilon=.87, p=.0083\right]$. An ANOVA for $\mathrm{C} 3$ and $\mathrm{C} 4$ with the factors task (symmetry, aesthetics), answer (yes, no), and channel (C3, C4) revealed a main effect for channel $[F(1,8)=20.38$,

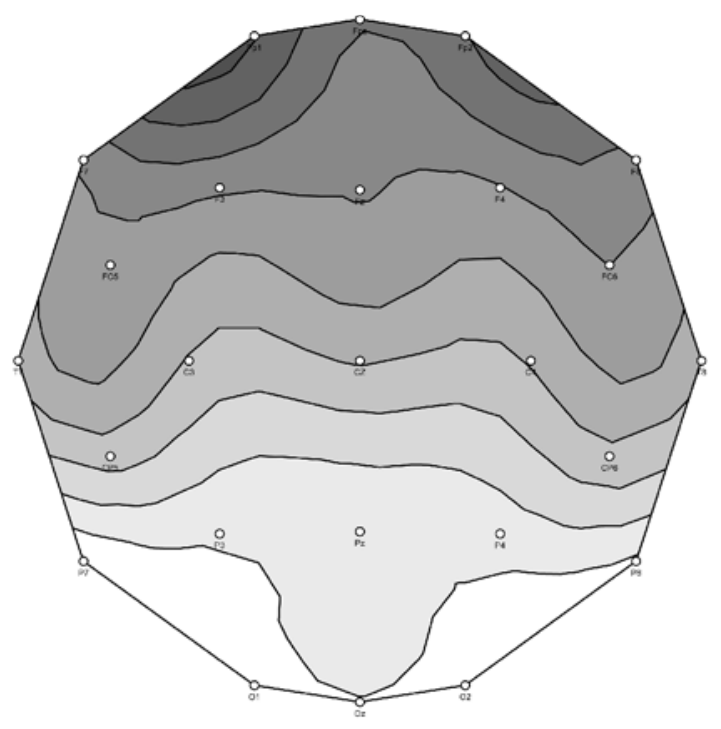

symmetric - not symmetric $600 \ldots 1,100 \mathrm{msec}$

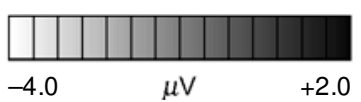

Figure 4. Isopotential contour plot, posterior sustained negativity effect in the descriptive symmetry judgment task condition. Mean difference potentials were plotted, symmetric minus not symmetric in the time window from 600 to $1,100 \mathrm{msec}$ after stimulus onset. 

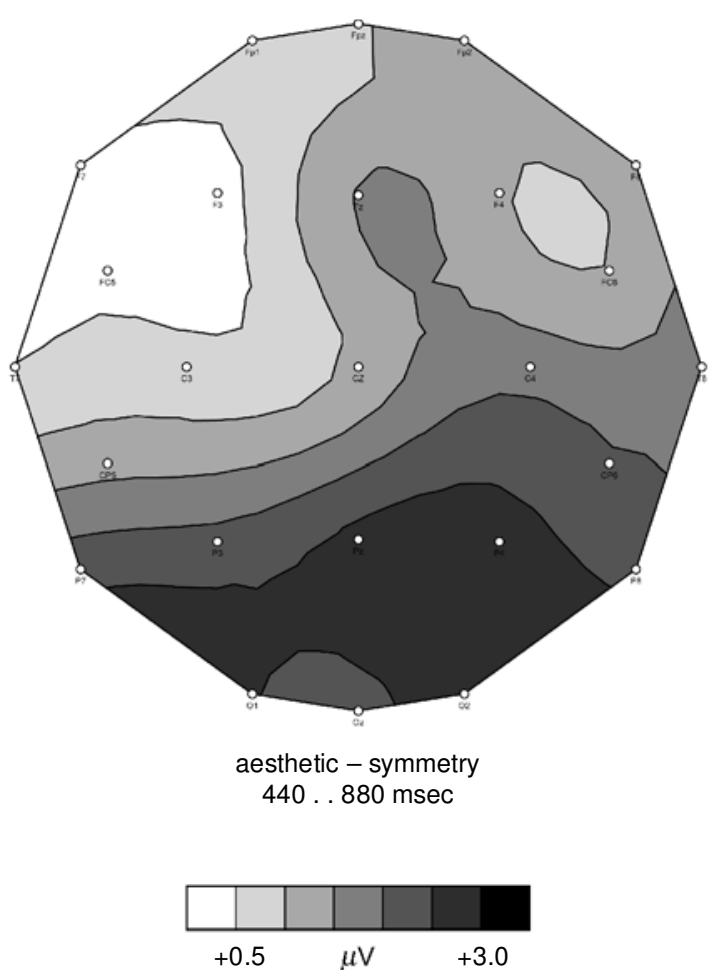

Figure 5. Isopotential contour plot, right hemisphere lateralization effect of the LPP in the evaluative task condition relative to the descriptive judgment task. Mean difference potentials were plotted, aesthetic judgment minus symmetric judgment in the time window from 440 to $880 \mathrm{msec}$ after stimulus onset.

$\left.M S_{\mathrm{e}}=4.02, p=.002\right]$, an interaction for task $\times$ answer $\left[F(1,8)=16.06, M S_{\mathrm{e}}=1.64, p=.0039\right]$, and, furthermore, an interaction for task $\times$ channel $[F(1,8)=11.36$, $\left.M S_{\mathrm{e}}=0.41, p=.0098\right]$. No other effect was significant: task $(F<1)$; answer $\left[F(1,8)=2.75, M S_{\mathrm{e}}=7.42, p=\right.$ .1359]; answer $\times$ channel $(F<1)$; task $\times$ answer $\times$ channel $(F<1)$. The interaction was further investigated for task revealing a larger effect of channel under the aesthetics task $\left[F(1,8)=24.66, M S_{\mathrm{e}}=2.54, p=.0011\right]$ than under the symmetry task $\left[F(1,8)=12.66, M S_{\mathrm{e}}=\right.$ $1.89, p=.0074]$ (see Figure 5).

\section{DISCUSSION}

In the present study, we investigated descriptive symmetry judgment and evaluative aesthetic judgment processes. Identical stimuli were employed in both judgment tasks in order to control perceptual processes and thus isolate judgmental processes. Combined behavioral, electrophysiological, and judgment analysis measures were used. This procedure allows the co-registration of behavioral and electrophysiological data also on an individual case basis.

By means of judgment analysis, individual case models and group models replicated previous findings on symmetry and complexity determinations of aesthetic judgments of beauty of novel graphic patterns, as predicted. Converging with results by Jacobsen (in press), substantial individual differences in judgment strategies were also revealed. Cue use and the degree of linear predictability differed considerably between participants. The individual models, however, proved to be considerably stable over the course of 3 days between the Phase 1 test and the main experiment. Given these individual results, an inaccurate account of the behavioral judgment data would result if the aesthetic judgment data were to be represented solely by a group model based on average data. ERP computation was contingent on the individual evaluative judgments. With this approach, individual differences were controlled in the comparative study of descriptive and evaluative judgment processes.

Extending previous findings, the present study demonstrated that the brain dissociated beautiful from notbeautiful patterns as early as $300-400 \mathrm{msec}$ after stimulus onset. In this time window, the not-beautiful judgments under the evaluative task elicited an early frontocentral phasic negativity (see Figure 3). It suggests that negative and positive evaluations differ in character, which converges with previous electrophysiological findings (see, e.g., Ito, Larsen, Smith, \& Cacioppo, 1998). The scalp topography of this deflection is congruent with frontal cortex involvement. Recent fMRI brain imaging studies have shown that the anterior frontomedian cortex (BA 10/9) is involved in evaluative judgment (e.g., Zysset, Huber, Ferstl, \& von Cramon, 2002; Zysset, Huber, Samson, Ferstl, \& von Cramon, 2003). These data suggest that the present early negativity was generated in the anterior frontomedian cortex. The present ERP topography, of course, is also consistent with other generator configurations, none of which, however, is equally likely. A bivariate evaluative response system is supported by a growing body of evidence, both neuroscientific (Ashby, Isen, \& Turken, 1999; Cacioppo \& Berntson, 1994; Russell \& Carroll, 1999) and behavioral (see also Hastie, 2001 , for a review). In addition, there are reports of neurological cases that show selective impairments of negative evaluative responses due to neural damage (e.g., Park et al., 2001). These studies also suggest that positive and negative evaluations are subserved, in part, by distinct neural structures. Consequently, it appears likely that the early frontal negativity reflects the operation of a processing stage that is involved in negative aesthetic evaluations, but not in positive evaluations or descriptive judgments of symmetry.

The evaluative judgment task elicited a stronger righthemisphere lateralization of the LPP around $600 \mathrm{msec}$ after stimulus onset. This lateralization effect reflects a stronger right-hemisphere involvement of evaluative processes as compared with descriptive processes. It extends previous findings of Cacioppo and colleagues (Cacioppo et al., 1993; Cacioppo, Crites, \& Gardner, 1996; Crites \& Cacioppo, 1996; Ito \& Cacioppo, 1999), because the present effect was observed despite the use of different material, a different task, and a different exper- 
imental design from those in Cacioppo and colleagues' original studies. This suggests that the LPP right lateralization reflects rather general processing characteristics of evaluative categorization. The temporal course indicates that decisions about responses were prepared in this time window, whereas overt responses were executed later, 1,000 msec after stimulus onset. The exact right hemisphere localization of the neural origins of this LPP ERP effect still remains unclear.

The symmetry judgment task elicited a sustained posterior negativity from 600 to $1,100 \mathrm{msec}$ after stimulus onset, largest at occipital sites for symmetric judgments relative to the other three conditions (Figure 4). This effect's scalp distribution suggests that it was most likely generated in the occipital cortex (van der Zwan, Leo, Joung, Latimer, \& Wenderoth, 1998). Participants engaged in sustained visual analysis of the stimuli in order not to miss a violation of symmetry, before they decided that a picture was symmetric - although the task was relatively easy. They did this only in the descriptive symmetry task condition. This longer lasting visual analysis was reflected by a sustained negativity. It was necessary only in the symmetric condition, because once nonsymmetry is detected in a stimulus, no further analysis is necessary.

The topographic ERP differences showed that participants did not merely perform a symmetry analysis in order to derive an aesthetic judgment, although aesthetics and symmetry were clearly correlated behaviorally. During the main experiment, the descriptive symmetry task was performed faster than the evaluative judgment task even though participants had not performed the symmetry task during the Phase 1 test. In other words, the expected difference was observed, despite the fact that participants had no training in the symmetry judgment task (cf. the results found by Mandler \& Shebo, 1983).

Correlational analyses of individual symmetry cue use (beta weights of the judgment models) and ERP measures were conducted, using Spearman's rank correlation. Participants that relied more on symmetry as a cue for aesthetic judgments (high beta weights; Table 1) showed a smaller amplitude of the early, frontal negativity $(r \mathrm{~s}=$ $-.9, p<.05$ ). That is, more systematic judgment resulted in less early negative evaluation. In addition, these participants showed a larger occipital symmetry analysis effect $(r \mathrm{~s}=.9, p<.05)$, which also set in earlier $(r \mathrm{~s}=-.9$, $p<.05)$. These post hoc analyses have heuristic value and should be considered as preliminary, given the sample size of 9 participants and the number of tests conducted without alpha adjustment. It may be speculated, however, that the use of a systematic rule to derive aesthetic judgments of beauty of novel graphic pattern leads to a reduced aesthetic impression formation, as ref lected by the early frontal negativity effect. When positive and negative evaluative categorizations are carried out, as reflected by the LPP, no such differences are observed. Both evaluative judgments likewise differ from descriptive ones, as indexed by the LPP right-lateralization effect. In sum, active evaluative judgments are performed by an early impression formation following $300 \mathrm{msec}$ after stimulus onset, most likely performed by anterior frontomedian cortical structures, and an evaluative categorization around $600 \mathrm{msec}$ that has a right-hemisphere preponderance of less clear cortical origin.

\section{REFERENCES}

American Electroence Phalographic Society (1991). American Electroencephalographic Society guidelines for standard electrode position nomenclature. Journal of Clinical Neurophysiology, 8, 200202.

Ashby, F. G., Isen, A. M., \& Turken, A. U. (1999). A neuropsychological theory of positive affect and its influence on cognition. Psychological Review, 106, 529-550.

BERLYNE, D. E. (1963). Complexity and incongruity variables as determinants of exploratory choice and evaluative ratings. Canadian Journal of Psychology, 17, 274-290.

Berlyne, D. E. (1970). Novelty, complexity, and hedonic value. Perception \& Psychophysics, 8, 279-286.

Berlyne, D. E. (1971). Aesthetics and psychobiology. New York: Appleton-Century-Crofts.

BERLYNE, D. E. (ED.) (1974). Studies in the new experimental aesthetics: Steps toward an objective psychology of aesthetic appreciation. Washington, DC: Hemisphere Publishing Corporation.

BREHMER, B., \& JOYCE, R. B. (EDS.) (1988). Human judgment: The SJT view. Amsterdam: North-Holland.

CAcioppo, J. T., \& Berntson, G. G. (1994). Relationships between attitudes and evaluative space: A critical review, with emphasis on the separability of positive and negative substrates. Psychological Bulletin, 115, 401-423.

Cacioppo, J. T., Crites, S. L., Berntson, G. G., \& Coles, M. G. H. (1993). If attitudes affect how stimuli are processed, should not they affect the event-related brain potential? Psychological Science, 4, 108-112.

Cacioppo, J. T., Crites, S. L., \& Gardner, W. L. (1996). Attitudes to the right: Evaluative processing is associated with lateralized late positive event-related brain potentials. Personality \& Social Psychology Bulletin, 22, 1205-1219.

Cacioppo, J. T., Crites, S. L., Gardner, W. L., \& Berntson, G. G. (1994). Bioelectrical echoes from evaluative categorizations: I. A late positive brain potential that varies as a function of trait negativity and extremity. Journal of Personality \& Social Psychology, 67, $115-125$

COOKsey, R. W. (1996). Judgment analysis: Theory, methods, and applications. San Diego: Academic Press.

CRITES, S. L., \& CACIOPPO, J. T. (1996). Electrocortical differentiation of evaluative and nonevaluative categorizations. Psychological Science, 7, 318-321.

Crites, S. L., Cacioppo, J. T., Gardner, W. L., \& Berntson, G. G. (1995). Bioelectrical echoes from evaluative categorization: II. A late positive brain potential that varies as a function of attitude registration rather than attitude report. Journal of Personality \& Social Psychology, 68, 997-1013.

CUPCHIK, G. C. (1992). From perception to production: A multilevel analysis of the aesthetic process. In G. C. Cupchik \& J. Laszlo (Eds.), Emerging visions of the aesthetic process (pp. 183-199). Cambridge: Cambridge University Press.

Eisenman, R. (1967). Complexity-simplicity: I. Preference for symmetry and rejection of complexity. Psychonomic Science, 8, 169-170.

Eisenman, R., \& Gellens, H. K. (1968). Preference for complexitysimplicity and symmetry-asymmetry. Perceptual \& Motor Skills, 26, 888-890.

EYSENCK, H. J., \& HAWKER, G. W. (1994). The taxonomy of visual aesthetic preferences: An empirical study. Empirical Studies of the Arts, 12, 95-101.

FeCHNER, G. T. (1876). Vorschule der Aesthetik [Experimental Aesthetics; "Pre-school" of aesthetics]. Leipzig: Breitkopf \& Härtel. GARDNER, H. (1985). The mind's new science. A history of the cognitive revolution. New York: Basic Books. 
HAmmond, K. R., Stewart, T. R., Brehmer, B., \& Steinmann, D. O. (1975). Social judgment theory. In M. F. Kaplan \& S. Schwartz (Eds.), Human judgment and decision processes (pp. 271-312). New York: Academic Press.

Hastie, R. (2001). Problems for judgment and decision making. Annual Reviews of Psychology, 52, 653-683.

ITO, T. A., \& CACIOPPO, J. T. (1999). The psychophysiology of utility appraisals. In D. Kahneman, E. Diener, \& N. Schwarz (Eds.), Wellbeing: Foundations of hedonic psychology (pp. 470-488). New York: Russell Sage.

ITO, T. A., \& CACIOPPO, J. T. (2000). Electrophysiological evidence of implicit and explicit categorization processes. Journal of Experimental Social Psychology, 36, 660-676.

Ito, T. A., LARSE N, J. T., SMith, N. K., \& CACioppo, J. T. (1998). Negative information weighs more heavily on the brain: The negativity bias in evaluative categorizations. Journal of Personality \& Social Psychology, 75, 887-900.

JACOBSEN, T. (2002). Kandinsky's questionnaire revisited: Fundamental correspondence of basic colors and forms? Perceptual \& Motor Skills, 95, 903-913.

JACOBSEN, T. (2004). Individual and group modeling of aesthetic judgment strategies. British Journal of Psychology, 95, 41-56.

JACOBSEN, T., \& HÖFEL, L. (2001). Aesthetics electrified: An analysis of descriptive symmetry and evaluative aesthetic judgment processes using event-related brain potentials. Empirical Studies of the Arts, 19, 177-190.

JACOBSEN, T., \& HöFel, L. (2002). Aesthetic judgments of novel graphic patterns: Analyses of individual judgments. Perceptual \& Motor Skills, 95, 755-766.

KERSTEEN-TUCKER,Z. (1991). Long-term repetition priming with symmetrical polygons and words. Memory \& Cognition, 19, 37-43.

KoNECNI, V. J. (1979). Determinants of aesthetic preference and effects of exposure to aesthetic stimuli: Social, emotional and cognitive factors. Progress in Experimental Personality Research, 9, 149-197.

MAndle R, G. (1982). The structure of value: Accounting for tastes. In M. S. Clark \& S. T. Fiske (Eds.), Affect and cognition: The seventh annual Carnegie symposium on cognition (pp. 3-36). Hillsdale, NJ: Erlbaum.

Mandler, G., \& Shebo, B. J. (1983). Knowing and liking. Motivation \& Emotion, 7, 125-144.

MARTINDAle, C. (1988). Aesthetics, psychobiology, and cognition. In F. H. Farley \& R. W. Neperud (Eds.), The foundation of aesthetics, art and art education (pp. 7-42). New York: Praeger.

MCCALl, W. A. (1939). Measurement. New York: Macmillan.

MCCARThy, G., \& WoOd, C. C. (1985). Scalp distributions of eventrelated potentials: An ambiguity associated with analysis of variance models. Electroencephalography \& Clinical Neurophysiology, 62, 203-208.

OLDFIELD, R. C. (1971). The assessment and analysis of handedness: The Edinburgh inventory. Neuropsychologia, 9, 97-113.
Park, N. W., Conrod, B., Rewilak, D., Kwon, C., GaO, F., \& Black, S. E. (2001). Automatic activation of positive but not negative attitudes after traumatic brain injury. Neuropsychologia, 39, 7-24.

PASHler, H. (1990). Coordinate frame for symmetry detection and object recognition. Journal of Experimental Psychology: Human Perception \& Performance, 16, 150-163.

Petty, R. E., Wegener, D. T., \& Fabrigar, L. R. (1997). Attitudes and attitude change. Annual Review of Psychology, 48, 609-647.

RitTERFELD, U. (2002). Social heuristics in interior design preferences. Journal of Environmental Psychology, 22, 369-386.

Russell, J. A., \& CARroll, J. M. (1999). On the bipolarity of positive and negative affect. Psychological Bulletin, 125, 3-30.

Schupp, H. T., Cuthbert, B. N., Bradley, M. M., Cacioppo, J. T., ITo, T., \& LANG, P. J. (2000). Affective picture processing: The late positive potential is modulated by motivational relevance. Psychophysiology, 37, 257-261.

SCHWARZ, N. (1988). Stimmung als Information: Zum Einfluss von Stimmungen und Emotionen auf evaluative Urteile [Mood as information: The influence of moods and emotions on evaluative judgments]. Psychologische Rundschau, 39, 148-159.

StEWART, T. R. (1988). Judgment analysis: Procedures. In B. Brehmer \& C. R. B. Joyce (Eds.), Human judgment: The SJT view (pp. 41-74). Amsterdam: North-Holland.

VAN DER ZWAN, R., Leo, E., Joung, W., LATIMER, C., \& Wenderoth, P. (1998). Evidence that both area V1 and extrastriate visual cortex contribute to symmetry perception. Current Biology, 8, 889-892.

Wenderoth, P. (1994). The salience of vertical symmetry. Perception, 23, 221-236.

WHITFIELD, A. (1984). Individual differences in evaluation of architectural colour: Categorization effects. Perceptual \& Motor Skills, 59, 183-186. ZAJONC, R. B. (1980). Feeling and thinking: Preferences need no inferences. American Psychologist, 35, 151-175.

Zysset, S., Huber, O., Ferstl, E. [C.], \& von Cramon, D. Y. (2002). The anterior frontomedian cortex and evaluative judgment: An fMRI study. NeuroImage, 15, 983-991.

Zysset, S., Huber, O., SAmson, A., Ferstl, E. C., \& von Cramon, D. Y. (2003). Functional specialization within the anterior medial prefrontal cortex: A functional magnetic resonance imaging study with human subjects. Neuroscience Letters, 335, 183-186.

\section{NOTE}

1. In addition, an additional exploratory analysis using separate repeated measures ANOVAs in 20-msec time windows over four midline electrode sites $(\mathrm{Fz}, \mathrm{Cz}, \mathrm{Pz}, \& \mathrm{Oz})$ was used to identify substantial effects, their time windows, and topographical variations. A second similar exploratory analysis tested hemispheric differences (C3, C4). ERP effects were taken to be substantial only if they resulted in significant effects in three consecutive 20 -msec time windows. The results of this analysis were redundant and converged with the visual inspection. 


\section{APPENDIX}

\section{Intercorrelations of Predictors}

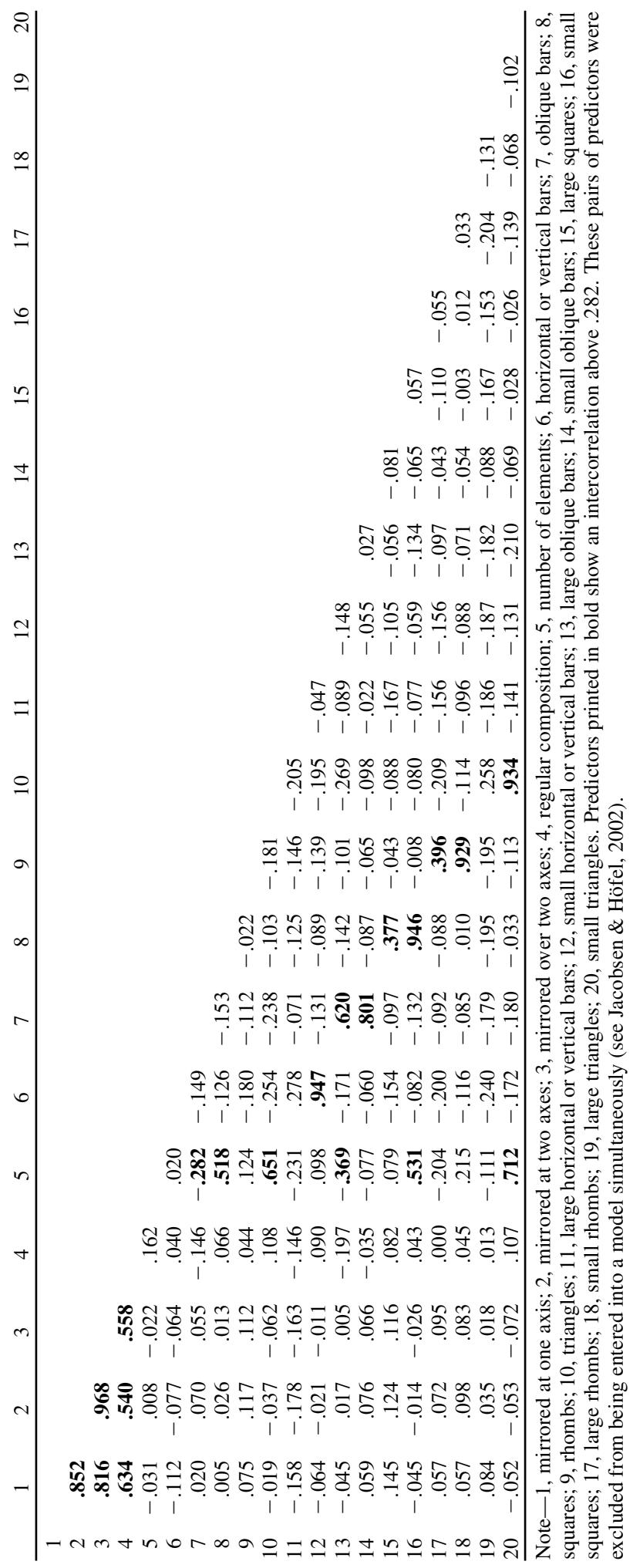

